Available online at www.sciencedirect.com

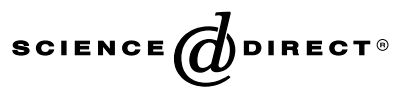

Ocean Modelling xxx (2005) xxx-xxx

\section{Ocean \\ Modelling}

www.elsevier.com/locate/ocemod

\title{
An energy-diagnostics intercomparison of coupled ice-ocean Arctic models
}

\author{
Petteri Uotila $^{\text {a,* }}$, David M. Holland ${ }^{b}$, Miguel A. Morales Maqueda ${ }^{b}$ \\ Sirpa Häkkinen ${ }^{c}$, Greg Holloway ${ }^{\mathrm{d}}$, Michael Karcher ${ }^{\mathrm{f}}$, Frank Kauker ${ }^{\mathrm{f}}$ \\ Michael Steele ${ }^{\mathrm{e}}$, Nikolai Yakovlev ${ }^{\mathrm{g}}$, Jinlun Zhang ${ }^{\mathrm{e}}$, Andrey Proshutinsky ${ }^{\mathrm{h}}$ \\ ${ }^{a}$ Center for Atmosphere-Ocean Science, Courant Institute of Mathematical Sciences, New York University, NYU, \\ 200 Water Street Apt. 703, New York, NY 10038-3515, USA \\ ${ }^{\mathrm{b}}$ Center for Atmosphere-Ocean Science, Courant Institute of Mathematical Sciences, New York University, NY, USA \\ ${ }^{\mathrm{c}}$ NASA/Goddard Space Flight Center, Greenbelt, MD, USA \\ ${ }^{\mathrm{d}}$ Institute of Ocean Sciences, Sidney, BC, Canada \\ ${ }^{\mathrm{e}}$ University of Washington, Seattle, USA \\ ${ }^{\mathrm{f}}$ Alfred Wegener Institute, Bremerhaven, Germany \\ ${ }^{\mathrm{g}}$ Institute of Numerical Mathematics Russian Academy of Science, Moscow, Russia \\ ${ }^{\mathrm{h}}$ WHOI, Woods Hole, USA
}

Received 12 May 2004; received in revised form 9 November 2004; accepted 9 November 2004

\begin{abstract}
Monthly energetics of the Arctic Ocean are estimated based on results from six different coupled iceocean models. The components of the kinetic, potential and available potential energies, energy conversion and forcing rates are studied. The energy balances derived from the models differ significantly in the abyss, notably regarding the conversion of potential and kinetic energies. The models produce arctic boundary undercurrents controlled by the non-geostrophic components of the momentum equation, like advection and friction. Discrepancies exist where the modeled boundary currents are located and how completely the flow circulates around the Arctic Ocean. Two models produce cyclonic circulation, which is strongest
\end{abstract}

\footnotetext{
${ }^{*}$ Corresponding author. Present address: School of Geography and Environmental Science, Monash University, VIC 3800, Australia. Tel.: +61 39905 2269; fax: +61 399052948.

E-mail address: uotila@cims.nyu.edu (P. Uotila).
} 


\section{ARTICLE IN PRESS}

at the depths of 300-800 m. The initial stratification, based on observations, contains a marked gradient of the available potential energy between the Eurasian and Canadian Basins with two corresponding circulation cells. The stratification is modified by the modeled circulation systematically so that this gradient vanishes. The models aim to produce a closer match toward the expected circulation, but result in a deviation from the observed, initial stratification.

(c) 2004 Elsevier Ltd. All rights reserved.

Keywords: Arctic zone; Polar oceanography; Modeling; Intercomparison; Energy balance

\section{Introduction}

The Arctic Ocean Model Intercomparison Project (AOMIP) is an international collaborative effort that has been established to perform a detailed analysis of the performance of state-ofthe-art coupled ice-ocean models of the Arctic Ocean (Proshutinsky et al., 2001; Steele et al., 2001a). The AOMIP www-site is located at the URL: http://fish.cims.nyu.edu/project_aomip/ overview.html.

One essential diagnostic of model performance is the total energy content within a model domain and the manner in which that energy is distributed in its various forms, such as kinetic, potential, and internal. Additionally, temporal and spatial variability of energy between the models can be compared. Quantifying the sources and sinks of energy is also an important aspect of obtaining an overall energy budget for the model domain. Understanding the Arctic Ocean energy balance is important because it can strengthen our understanding of the links between the polar regions and the global climate system. The energetics analysis is chosen to be an AOMIP research topic, because it integrates the outcome of modeled physical processes and makes them applicable for mutual comparison.

An important term of the energy balance is conversion of the potential energy (PE) to the kinetic energy (KE), and the sign of this conversion. According to Oort et al. (1994), the conversion rate is not generally properly represented by numerical models. In eddy-resolving models, however, the conversion seems always to be a source of PE and varies locally (Ivchenko et al., 1997). Because the participating models do not resolve eddies, only the mean components of energy are studied. The PE-KE balance is connected to the mixing and thermohaline circulation (Huang, 1999). An energy intercomparison can therefore provide high-level information about the model parameterizations of mixing processes, thermohaline circulation, currents, and river freshwater input.

Ocean energetics and the physical relevance of ocean models has been addressed in a recent paper by Wunsch and Ferrari (2004). Models are often tuned and constrained to fit to the present climate conditions producing circulations that appear realistic, and, in so doing, perhaps compensating for incorrect model energetics.

In this paper, we carry out some steps toward a comprehensive accounting and intercomparison of the energy budgets of the various AOMIP models. The analysis is focused on the kinetic, potential, available potential and internal heat energy components by comparing the model data with observed climatology. In Section 2, the methods applied to estimate the energy components and the balance of kinetic energy are presented. In Section 3 the different AOMIP models are suc- 
cinctly described and the AOMIP protocol is presented. In Section 4, results based on the methods discussed in Section 2 are presented. Finally in Section 5, conclusions are drawn from the analysis.

\section{Methods}

\subsection{Internal heat energy}

The internal heat energy (IE) of a volume element is defined as

$$
\mathrm{IE}=c_{0} \rho T,
$$

where $\rho$ is the density of ocean, $c_{0}$, is the specific heat at constant pressure for ocean waters, assumed to be $3950 \mathrm{Jkg}^{-1} \mathrm{~K}^{-1}$ (Apel, 1987). $T$ is the water temperature in Celsius.

\subsection{Potential energy and available potential energy ( $A P E$ )}

The total potential energy (PE) of a volume element is defined as

$$
\mathrm{PE}=\rho g z,
$$

where $z$ is the vertical coordinate and $g$ is the acceleration due to gravity. We calculate APE following the definition (Lorenz, 1955):

$$
\int_{V} \operatorname{APE} \mathrm{d} V=\int_{V}\left(\mathrm{PE}-\rho_{r} g z_{r}\right) \mathrm{d} V,
$$

where the second term on the right represents a reference potential energy RPE that is subtracted from PE and $V$ is the basin volume. The reference level $z_{r}$ is defined to correspond to the minimum potential energy state (Huang, 1998; Winters et al., 1995). This amount of energy can be transferred to KE via adiabatic redistribution of the density field. While the PE can be calculated by integrating the density distribution of the fluid, the estimation of the reference state RPE requires knowledge of the reference density distribution $\rho_{r}\left(z_{r}\right)$.

Oort et al. (1989) utilized a formula for APE following from a quasi-geostrophic approximation as:

$$
\operatorname{APE}_{0}=-\frac{1}{2} g(\rho-\tilde{\rho})^{2}\left(\frac{\partial \widetilde{\rho_{\phi}}}{\partial z}\right)^{-1} .
$$

Here $\sim$ represents the horizontal averaging operator, $\rho_{\phi}$ is the potential density respect to the surface, and $\partial \rho_{\phi} / \partial z$ is the vertical gradient of $\rho_{\phi}$.

We denote the available potential energy estimated in a volume element from (4) as $\mathrm{APE}_{0}$. The application of the exact definition of APE is difficult (Huang, 1998), and we calculate APE as $\mathrm{APE}_{0}$. We assume $\tilde{\rho}$ to be the horizontal average of the global density field and $\partial \rho_{\phi} / \partial z$ to be 
the horizontal average of the global potential density gradients analogously to Oort et al. (1989). Accordingly $\mathrm{APE}_{0}$ describes the deviation of density from the global mean. We can compare our estimates to those of Oort et al. (1989) as well.

\subsection{Kinetic energy ( $K E)$}

The kinetic energy of the models is estimated from the monthly velocity fields. In addition to the annual average KE fields the areas of the highest variability are compared. An accurate eddy kinetic energy (EKE) analysis is not possible due to the low temporal and spatial resolution of the available model data.

The kinetic energy (KE) in a volume element is defined as

$$
\mathrm{KE}=\frac{1}{2} \rho \vec{v} \cdot \vec{v}
$$

where $\vec{v}$ is the velocity vector of the water motion. For the AOMIP models $\vec{v}$ is composed of horizontal velocity components (see Section 2.3.1).

\subsubsection{Balance of $K E$}

The balance of kinetic energy (KE) is

$$
\partial_{t} \mathrm{KE}+(\vec{v} \cdot \nabla) \mathrm{KE}=-(\vec{v} \cdot \nabla) p+\nabla \cdot K \nabla \mathrm{KE}-\rho \vec{v} \cdot \nabla \Phi-\rho \varepsilon,
$$

where $K$ is the eddy diffusion coefficient and $\varepsilon$ is called the dissipation rate. Eq. (6) is obtained from taking the scalar product of the momentum equation with $\rho \vec{v}$. Models are hydrostatic and non-tidal and

$$
\begin{aligned}
& \nabla \Phi=\partial_{z} \Phi \hat{k}=-g \hat{k}, \\
& \partial_{z} p=-g \rho, \\
& \rho \vec{v}_{H} \cdot \nabla \Phi=0, \\
& \mathrm{KE}=\frac{1}{2} \rho\left(u^{2}+v^{2}\right) .
\end{aligned}
$$

According to (7a) the gradient of the gravitational potential $\nabla \Phi$ is assumed to be strictly vertical. Thus the PE $\leftrightarrow \mathrm{KE}$ exchange is enabled through the pressure term, the first RHS term in (6), only.

$$
\begin{aligned}
& \partial_{t} \mathrm{KE}+(\vec{v} \cdot \nabla) \mathrm{KE}=-(\vec{v} \cdot \nabla) p+\nabla \cdot K \nabla \mathrm{KE}-\rho \varepsilon \\
& A=P+F+D \\
& \rho \varepsilon_{\mathrm{L}}=K_{\mathrm{h}}\left(\partial_{x} \vec{v} \cdot \partial_{x} \vec{v}+\partial_{y} \vec{v} \cdot \partial_{y} \vec{v}\right)+K_{\mathrm{v}}\left(\partial_{z} \vec{v} \cdot \partial_{z} \vec{v}\right) .
\end{aligned}
$$




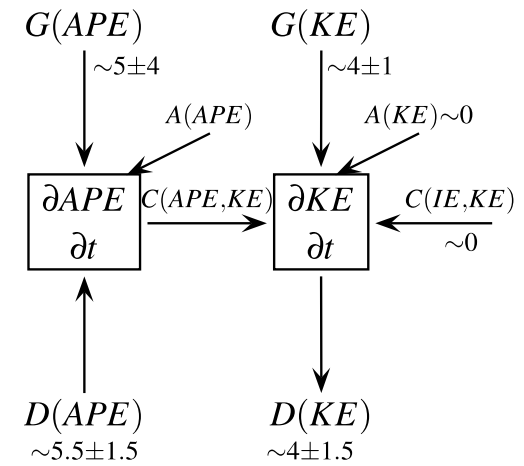

Fig. 1. A schematic energy diagram describing the potential (APE) and kinetic energy (IE) flow components in the ocean. Arrows indicate the positive direction of the flow. Estimates in $\mathrm{mW} \mathrm{m}{ }^{-2}$ derived from Oort et al. (1994) for the northern hemisphere. $G(\cdot)$ is the generation rate, $A(\cdot)$ advection and $D(\cdot)$ dissipation of the corresponding energy component. $C(\cdot, \cdot)$ stands for the conversion rate of two components of energy.

In (8b) $A$ describes the advection of mechanical energy, $P$ the conversion term, $F$ diffusion term, and $D=-\rho \varepsilon_{\mathrm{L}}$ is the dissipative term for the Laplacian friction. $K_{\mathrm{h}}$ and $K_{\mathrm{v}}$ are the horizontal and vertical viscosities, respectively. When applying biharmonic friction, the horizontal dissipative term is (Griffies and Hallberg, 2000) $\left(K_{\mathrm{h}}\right.$ is constant)

$$
D_{\mathrm{b}}=\rho \varepsilon_{\mathrm{b}}=K_{\mathrm{h}}\left(\partial_{x x} \vec{v} \cdot \partial_{x x} \vec{v}+\partial_{y y} \vec{v} \cdot \partial_{y y} \vec{v}\right) .
$$

One model (AWI) participating in this study applies the biharmonic parameterization.

A schematic diagram of the energy cycle in the ocean is presented in Fig. 1. Oort et al. (1994) estimated annual average of the conversion of APE to KE to be negative, $-0.45 \times 10^{3} \mathrm{~W} \mathrm{~m}^{-2}$, in the northern hemisphere, indicating $\mathrm{KE} \rightarrow \mathrm{APE}$ flux. This energy rate, however changes direction to $\mathrm{APE} \rightarrow \mathrm{KE}$ flux of $1-2 \times 10^{-3} \mathrm{~W} \mathrm{~m}^{-2}$ in the Arctic Ocean. They estimated the forcing rates of the kinetic energy, $G(\mathrm{KE})$, and the available potential energy, $G(\mathrm{APE})$, to be $4.2 \times 10^{-3} \mathrm{~W} \mathrm{~m}^{-2}$ and $5 \times 10^{-3} \mathrm{~W} \mathrm{~m}^{-2}$, respectively, for the northern hemisphere. Their corresponding values for the dissipation rates $D(\mathrm{KE})$ and $D(\mathrm{APE})$ were $4 \times 10^{-3} \mathrm{~W} \mathrm{~m}^{-2}$ and $5.4 \times 10^{-3} \mathrm{~W} \mathrm{~m}^{-2}$, respectively.

The forcing of KE can be estimated from the AOMIP wind data. For example by using wind stress of the AOMIP protocol and the AWI model ice and sea surface velocities, the average wind energy flux is $1.2 \times 10^{-3} \mathrm{~W} \mathrm{~m}^{-2}$. Estimates based on the other model data vary depending on the ice conditions. This is somewhat smaller than the estimate of Oort et al. (1994), but can be explained by relatively slow moving central Arctic ice and weaker winds than at lower latitudes.

We compute the energy fluxes in the deep ocean, where the time scales of motion are longest and the fluxes can be estimated from the monthly data with some accuracy. The vertically integrated deep sea energy fluxes of the AOMIP model data (see Section 4.3.5), are typically order of magnitude $10^{-7} \mathrm{~W} \mathrm{~m}^{-3} \times 10^{-3} \mathrm{~m}=10^{-4} \mathrm{~W} \mathrm{~m}^{-2}$, which are comparable, but smaller, to the estimates by Oort et al. (1994). The local time derivative, $\partial_{t} \mathrm{KE}$, is small in the abyss. Mean values derived from the model data are less than $10^{-9} \mathrm{~W} \mathrm{~m}^{-3}$ and more than two magnitudes smaller than the other flux components. Because we focus on the energy flux analysis to the deep ocean, we neglect $\partial_{t} \mathrm{KE}$ when looking the annual and spatial mean fluxes in Section 4.3.5, but admit that the time derivative may be of local importance. 


\section{ARTICLE IN PRESS}

\section{Data}

\subsection{Observational data}

The IE, PE and APE fields derived from the Polar Science Center Hydrographic Climatology v2.1 (PHC 2.1, Steele et al., 2001b) are utilized in the comparison. PHC was also used for the initial conditions and restoring of the models according to the AOMIP protocol.

\subsection{Simulated data}

The AOMIP models are forced with the same data, apply the same topographical dataset, have the same boundary conditions and some of the physical and numerical parameters, which in general, are defined to be uniform following the AOMIP protocol. The topographies of models are derived from the same dataset, but they are significantly different depending on the spatial resolution of the models. The wind and air temperature forcing are based on the NCEP/NCAR reanalysis, and is daily for the models, except the GSFC model which applies running monthly mean atmospheric forcing. Other forcing fields, such as precipitation, cloudiness and river runoff are from monthly climatologies.

Six models (AWI, GSFC, IOS, NYU, RAS, and UW models) are compared in this particular study: AWI model originates in the Alfred Wegener Institute, Germany; GSFC model is from the NASA/Goddard Space Flight Center, Greenbelt, USA; IOS model is from the Institute of Ocean Science, Sidney, Canada; NYU model is from the New York University, New York, USA; RAS model is from the Russian Academy of Science, Moscow, Russia; and UW model is from the University of Washington, Seattle, USA. The characteristics of the models and particular model runs studied in this paper are listed in Table 1. Details of the grid configuration and friction parameterization are listed in Table 2.

One may note that the vertical coordinate system varies between the models: AWI, IOS, RAS and UW models utilize a $z$-coordinate system, GSFC a $\sigma$-coordinate system and NYU a $\rho$-coordinate system. In addition, the parameterization of the friction term $F$ varies significantly. IOS model fields are daily averages stored once a month, while the other model data are monthly mean fields. AWI model restored surface ocean salinity (SSS) and UW model both surface ocean salinity and temperature (SST) during the whole 30 years experiment using a restoring time scale of 180

Table 1

Model descriptors

\begin{tabular}{llllll}
\hline Model & Ocean model & $\delta x$ & Vert. Dims. & Ice Dyn. & References \\
\hline AWI & MOM & $1 / 4^{\circ}$ & $z$-coord., 33 levels & VP & Karcher et al. (2003) \\
GSFC & POM & $0.9^{\circ} \times 0.7^{\circ}$ & $\sigma$-coord., 20 levels & Gener. visc. & Häkkinen (1999) \\
IOS & MOM & $1 / 2^{\circ}$ & $z$-coord., 29 levels & VP & Holloway and Sou (2002) \\
NYU & MICOM & $1 / 2^{\circ}$ & $\rho$-coord., 11 layers & Cav. fluid & Holland (2001) \\
RAS & Finite element & $1^{\circ}$ & $z$-coord., 16 levels & VP & Yakovlev (2003) \\
UW & MOM & $40 \mathrm{~km}$ & z-coord., 21 levels & VP & Zhang et al. (2000) \\
PHC & Climatology & $1^{\circ}$ & $z$-coord., 32 levels & & Steele et al. (2001b) \\
\hline
\end{tabular}




\section{ARTICLE IN PRESS}

Table 2

AOMIP model parameterizations

\begin{tabular}{lllllll}
\hline & Vertical grid & $\begin{array}{l}\text { Horizontal } \\
\text { grid }\end{array}$ & $K_{\mathrm{v}}\left(\mathrm{m}^{2} \mathrm{~s}^{-1}\right)$ & $K_{\mathrm{h}}$ & $C_{\mathrm{b}} 10^{-3}$ & $\begin{array}{l}\text { Restoring } \\
\text { after } 1958\end{array}$ \\
\hline AWI & Level & B-grid & $10^{-3}$ & Biharmonic & 1.2 & SSS \\
GSFC & Sigma & B-grid & TC (Mellor-Yamada) & Laplacian, Smagorinsky & Yes, $C_{\mathrm{b}}$ varies & No \\
IOS & Level & B-grid & $10^{-3}$ & Laplacian, Neptune & 1.2 & No \\
NYU & Isopycnal & C-grid & $10^{-5}$ & Laplacian, Smagorinsky & 2.5 & No \\
RAS & Level & A-grid & Prandtl & Laplacian & 1.3 & SSS \\
UW & Level & B-grid & $10^{-4}$ & Laplacian & No & SSS + SST \\
\hline
\end{tabular}

$C_{\mathrm{b}}$ is the drag coefficient of the bottom friction.

days. Rest of the models had surface salinity restoring only during the first 11 years of the integration using a restoring time scale of 180 days, except IOS, which did not apply restoring at all. The energetics results are based on the monthly fields of the last year of the AOMIP spin up run, over the period 1948-1978.

\section{Results}

For the analysis, a region approximately common to all the models was chosen (Fig. 2). Model data were interpolated to the common AOMIP grid. Results based on the interpolated data are discussed in Sections 4.1,4.2 and 4.3.1,4.3.2,4.3.3,4.3.4.

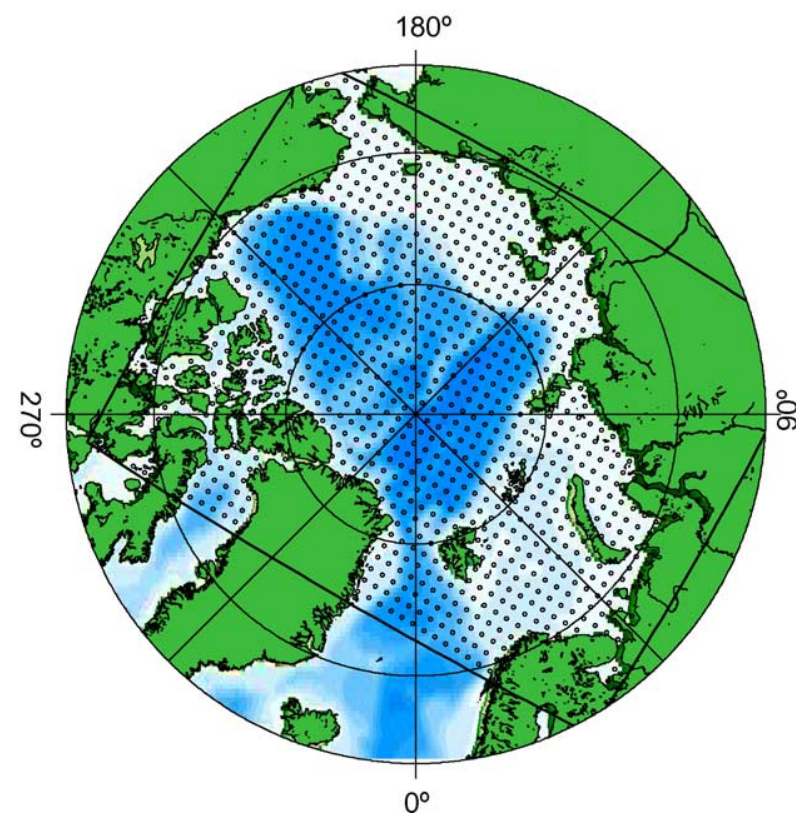

Fig. 2. The common intercomparison area for all models is outlined by the rectangular box. That area is represented by a latitude-longitude grid with $1^{\circ}$ spatial resolution and has rotated latitude-longitude coordinates with respect to true geographical latitude-longitude coordinates. It is referred to as the AOMIP grid. 


\section{ARTICLE IN PRESS}

The terms of the energy balance (8b) are based on the velocity and density gradients of the original, non-interpolated model grids (see Table 2). We focus on the deep water masses (below $500 \mathrm{~m}$ )-where pressure gradient and velocity fluctuations can be reasonably well assessed from monthly data. This part of the study is discussed in Section 4.3.5.

\subsection{Internal heat energy}

The global mean of IE from PHC, $47 \times 10^{11} \mathrm{~J} \mathrm{~m}^{-2}$, is close to the value $45 \times 10^{11} \mathrm{~J} \mathrm{~m}^{-2}$ estimated by Oort et al. (1989). IE in the Arctic Ocean is 1-2 orders of magnitude less (Table 3). RAS and NYU models have the warmest Arctic Ocean, while UW and AWI ones have the coldest. IOS and AWI IE mean values are closest to the climatological average.

The seasonal cycles of IE provided by the models are relatively coherent as presented in Fig. $3 \mathrm{~b}$. The NYU model seasonal cycle has the smallest amplitude. The PHC climatology has higher amplitude and less smooth seasonal cycle than the models.

The overall spatial pattern of IE is clearly similar for the models and most of the IE is located in the GIN (Greenland/Iceland/Norwegian Seas) and Barents seas and in the Fram Strait where the warm Atlantic water enters the Arctic Ocean flowing along the Siberian shelf break (Fig. 4b). The vertically integrated IE distributions follow closely the topography of the Canadian and Eurasian Basins. The model results deviate most in the GIN Seas (Fig. 4c). The models differ significantly how far into the Arctic Ocean the warm Atlantic water spreads. UW model produces the least inflow of the Atlantic water, while warm water inflow of AWI, GSFC and IOS models is close to the average field of PHC in Fig. 4a. The models have too warm water in the GIN Seas and in the Eurasian Basin, while the heat content of PHC seem to be somewhat higher in the Canadian Basin (Fig. 4d). In the GIN Seas the models might not have enough convection, causing heat loss to the atmosphere and therefore cooling the ocean. The individual model data shows that AWI and UW models have colder GIN Seas, resembling PHC, compared to the other models. In addition, a recent study by Gerdes et al. (in press) shows that the convection rate of AWI model is consistent with observations. NYU and RAS models have evidently too warm an Arctic Ocean. RAS model had relatively low horizontal resolution and thus wide channels connecting the Atlantic and the Arctic Ocean, which may have caused too strong an inflow of the Atlantic water.

NYU model has a relatively cold (and saline) Canadian Basin and a warm (less saline) Eurasian Basin forming a strong density gradient and geostrophic flow. NYU model has an ice-covered

Table 3

Annual mean values of the monthly energy components

\begin{tabular}{llccc}
\hline & PE $\left(10^{10} \mathrm{~J} \mathrm{~m}^{-2}\right)$ & $\mathrm{IE}\left(10^{8} \mathrm{~J} \mathrm{~m}^{-2}\right)$ & $\mathrm{APE}_{0}\left(10^{5} \mathrm{~J} \mathrm{~m}^{-2}\right)$ & $\mathrm{KE}\left(\mathrm{J} \mathrm{m}^{-2}\right)$ \\
\hline PHC, global & 6.0 & 605.0 & 5.7 & \\
PHC, arctic & 2.58 & -6.8 & 10.4 & 87 \\
AWI & 2.60 & -9.1 & 10.8 & 173 \\
GSFC & 2.60 & 2.1 & 10.5 & 126 \\
IOS & 2.60 & -3.9 & 8.92 & 11 \\
NYU & 2.60 & 5.0 & 19.5 & 47 \\
RAS & 2.59 & 15.6 & 6.64 & 92 \\
UW & 2.60 & -11.3 & 8.87 & \\
\hline
\end{tabular}



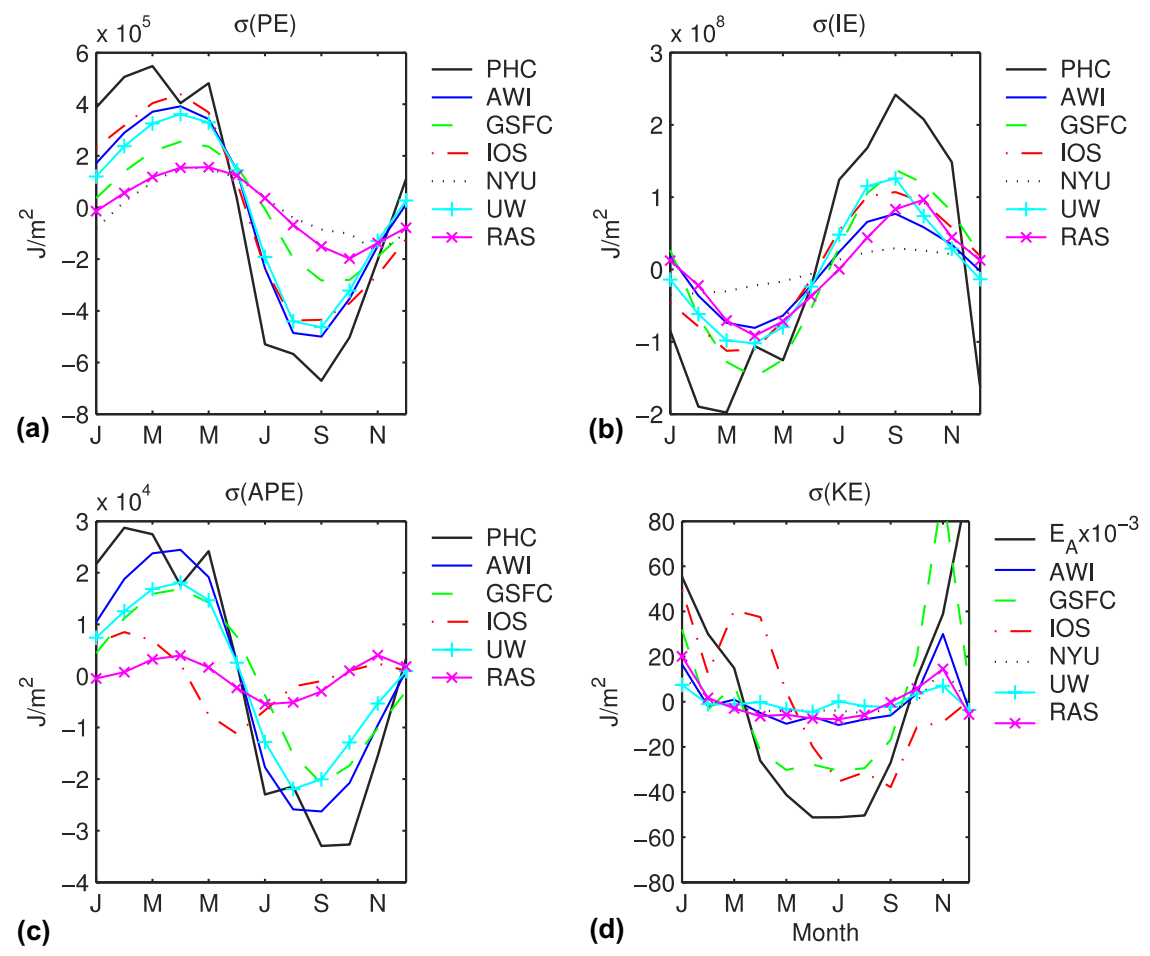

Fig. 3. Seasonal normalized time series of (a) potential energy, (b) internal heat energy, (c) available potential energy $\mathrm{APE}_{0}$, and (d) kinetic energy $\mathrm{KE} \cdot E_{A}$ is an estimated input of wind energy.

Barents sea where water remains warm without heat loss to the cold atmosphere. Modeled sea-ice conditions affect the forcing of kinetic energy, internal energy and available potential energy at the ice-ocean-atmosphere interface and the energetics of the ocean model. According to a modeling experiment by Holland et al. (1996), the Arctic Ocean circulation is weaker with smaller air-ocean stress, yet the basic circulation pattern remains unchanged. Calculation of forcing of the kinetic energy from monthly velocities produces small values under sea ice especially in the Barents Sea. This results in weak currents of NYU model and affects the circulation in the whole Arctic Ocean. The importance of the Barents Sea for the Arctic Ocean stratification is emphasized by Gerdes and Schauer (1997).

The seasonal variability of IE is biggest in the GIN Seas and the Barents Sea. All models also reveal variability along the Canadian coast and in the archipelago. These are the regions of seasonal ice cover or totally ice-free and due to this the energy exchange with the atmosphere is more intensive. The results follow the heat content estimates of Steiner et al. (2004). When compared with the PHC deviation, the models seem to reveal less variability along the Barents-Arctic shelf edge.

\subsection{Potential energy and available potential energy}

As with IE, the vertically integrated PE is dominated by the topography of the basin. In addition, the modeled PE seasonal cycles follow relatively close to each other (Fig. 3a). Again, PHC 


\section{ARTICLE IN PRESS}
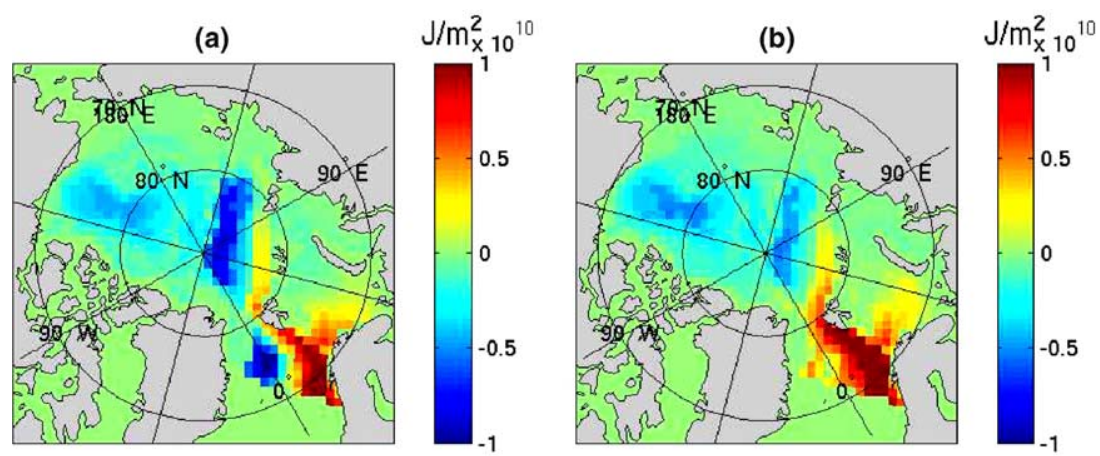

(c)

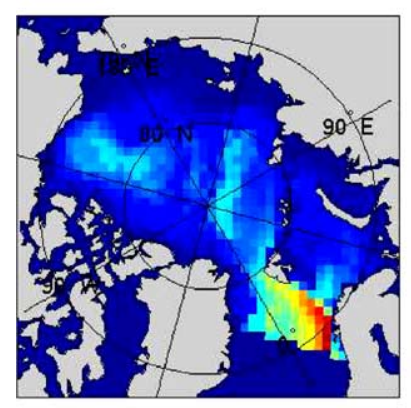

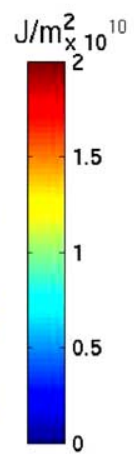

(d)

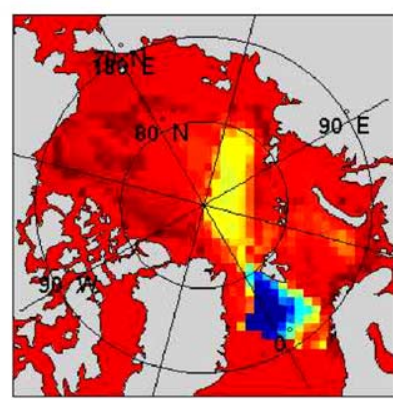

$\mathrm{J} / \mathrm{m}_{\mathrm{x} 10^{2}}^{9}$

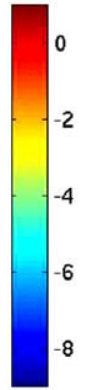

Fig. 4. Annual-average fields of internal heat energy IE for (a) PHC climatology, (b) the mean field of the model data, (c) the standard deviation field of the model data, and (d) bias (PHC-model mean) field in 1978. Note that the temperature data applied in the computation is relative to $0{ }^{\circ} \mathrm{C}$. The vertical integral extends from the sea floor to the surface.

climatology has the largest seasonal cycle, followed by AWI and UW, and IOS. PE seasonal fluctuation is four orders of magnitude less than its annual mean.

We calculate $\mathrm{APE}_{0}$ from (4), which depends on the inverse of the vertical gradient of the potential density that tends to be large in the deep ocean and the anomaly from the horizontally averaged density, which tends to be large near the surface. These two terms, based on relatively small differentials, produce a combination, which is quite sensitive to uncertainties in the source terms. Therefore significant differences due to the models and noise, produced by for example, numerical discretization, is difficult to distinguish. In the analysis we neglect the values of $\partial \widetilde{\rho_{\phi}} / \partial z<-8.4 \times 10^{-3} \mathrm{~kg} \mathrm{~m}^{-4}$, which are considered to be below the numerical accuracy.

$\mathrm{APE}_{0}$ mean values in Table 3 vary from $7 \times 10^{5} \mathrm{~J} \mathrm{~m}^{-2}$ (RAS) to $20 \times 10^{-5} \mathrm{~J} \mathrm{~m}^{-2}$ (NYU). RAS has the strong intrusion of warm Atlantic water producing stratification of the Arctic Ocean closer to the global average profile, while NYU model has anomalous stratification resulting from thick ice cover (ice thickness $\simeq 10 \mathrm{~m}$ ). The other models and PHC have $\mathrm{APE}_{0}$ of $10^{6} \mathrm{~J} \mathrm{~m}^{-2}$, about twice of the global average (Table 3 and Oort et al., 1994). Oort et al. (1994) obtained values of $4 \times 10^{5} \mathrm{~J} \mathrm{~m}^{-2}$ for the northern hemisphere based on the Levitus (1982) atlas for the ice-free ocean regions. The global $\mathrm{APE}_{0}$ field is illustrated in Fig. 5. The polar oceans, shallow marginal seas, North Atlantic Current and Kuroshio Current have high amounts of $\mathrm{APE}_{0}$ and water density in these regions deviate most from the average density profile of the oceans. 


\section{ARTICLE IN PRESS}

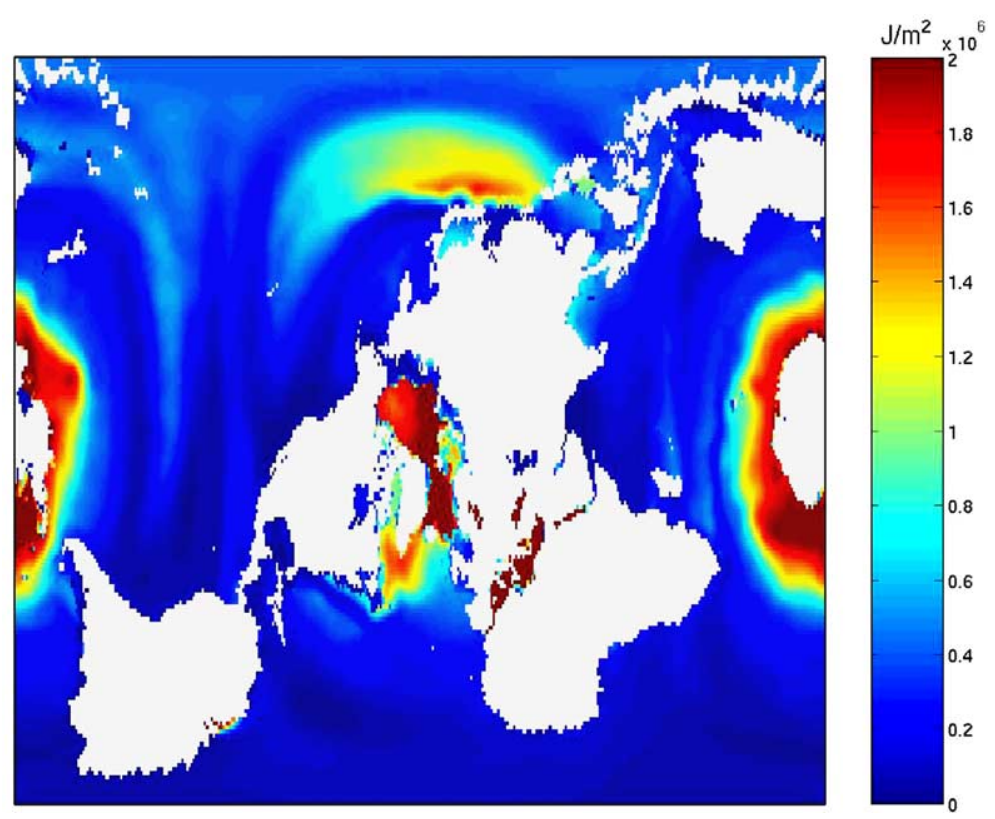

Fig. 5. Vertically integrated annual average oceanic $\mathrm{APE}_{0}$ density field based on the Polar science center Hydrographic Climatology (PHC) v. 2.1. from http://psc.apl.washington.edu/Climatology.html. The vertical integral extends from the sea floor to the surface. The Arctic Ocean is situated near the center of the plot.

$\mathrm{APE}_{0}$ seasonal fluctuations (Fig. 3c) are similar to PE, with higher values during the first six months, when the surface water becomes heavier by losing heat to the cold winter air and warms again during the latter half of the year due to the warm atmosphere. Most of the fluctuations occur in the seasonally ice covered regions, especially in the GIN and Barents seas where also the variability in the atmospheric conditions is the most significant.

The PHC APE ${ }_{0}$ spatial distribution in the Arctic Ocean reveals high $\mathrm{APE}_{0}$ values in the Eurasian Basin and the GIN Seas (Fig. 6a). PHC has less saline water in the Beaufort Gyre resulting in stronger stratification, which decreases $\mathrm{APE}_{0}$. None of the participating models produces this feature and the mean field of the model data does not reveal the difference between the $\mathrm{APE}_{0}$ of the Canadian and the Eurasian Basins (Fig. 6b). The models' deviation of $\mathrm{APE}_{0}$ is generally highest in the GIN and Barents seas, and along the Siberian shelf in the Eurasian Basin (Fig. 6c). The individual model data shows, that AWI has somewhat less $\mathrm{APE}_{0}$ in the Beaufort Gyre, but not as distinct as the climatology. UW has fresh water pool in the Beaufort Gyre, but with too limited dimensions.

$\mathrm{APE}_{0}$ from PHC climatology is on the average higher than $\mathrm{APE}_{0}$ from the model data in the Eurasian Basin, smaller in the GIN sea, and slightly smaller in the Beaufort Sea (Fig. 6d). In the GIN Seas models have on the average warmer, less saline water than PHC, which results in the higher deviation from the global average density profile $(\tilde{\rho})$ and higher $\mathrm{APE}_{0}$ in the region. In the Eurasian Basin, on the other hand, the modeled temperature is again on the average higher than PHC, but now resulting in smaller deviation from $\tilde{\rho}$ due to the higher salinity than PHC and therefore smaller $\mathrm{APE}_{0}$. In the Beaufort Sea the models are unable to simulate the layer of cold, less saline water shown by $\mathrm{PHC}$, which would increase $\mathrm{APE}_{0}$. 


\section{ARTICLE IN PRESS}

(a)

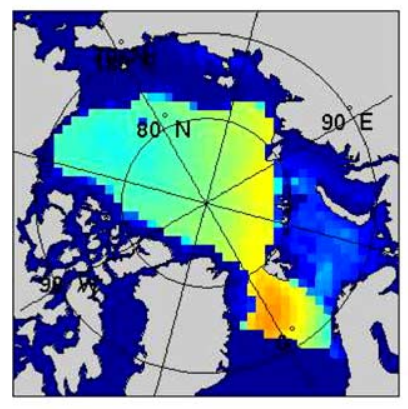

(c)

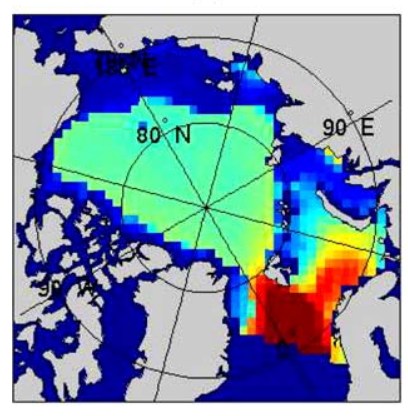

$\mathrm{J} / \mathrm{m}_{\times 10^{6}}^{2}$

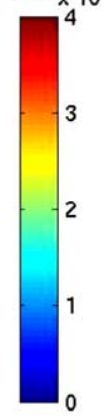

$\mathrm{J} / \mathrm{m}_{\times 10^{6}}^{2}$

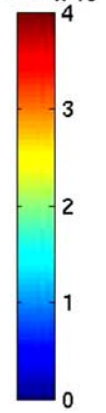

(b)

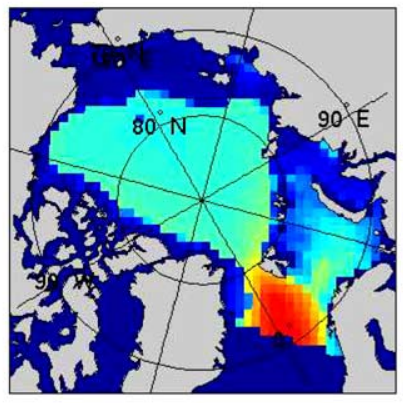

(d)

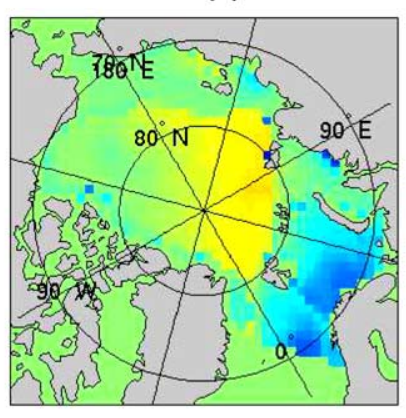

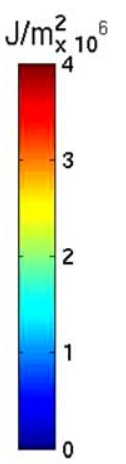

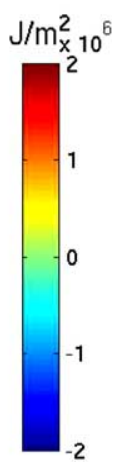

Fig. 6. Annual average fields of available potential energy $\mathrm{APE}_{0}$ for (a) $\mathrm{PHC}$ climatology, (b) the mean field of the model data, (c) the standard deviation field of the model data, and (d) bias (PHC model mean) field in 1978. The vertical integral extends from the sea floor to the surface.

\subsection{Kinetic energy}

The mutual coherence of KE between the models is much lower and the level of the relative variability much higher than with IE or PE. The mean KE values vary from 10 to $170 \mathrm{~J} \mathrm{~m}^{-2}$ (Table 3).

The geostrophic current and the subsequent KE was calculated from PHC hydrography, by choosing a level of no motion at the $1000 \mathrm{~m}$ depth. For comparison, the geostrophic current was also computed with the level of no motion at 3000, 2500, 2000, 1500 and $500 \mathrm{~m}$ depth. This changed the magnitude of the current, but, more importantly, the circulation pattern remained the same. KE derived from PHC provides lower limit when compared with the model data.

The geostrophic current is based on the density gradients and gives information about the vertical shear of the baroclinic flow only. One should keep in mind that the barotropic flow has no associated density gradient and can not be estimated from the horizontal density gradients. On the other hand, strong flows are likely to have strong shears being geostrophically compensated and disturbing density gradients. It is therefore plausible to assume that high density gradients, and geostrophic flow, identify regions of strong barotropic flow. This assumption was verified by computing geostrophic currents and KE from the modeled stratification and checked the regions of high density gradients matched with the regions of high KE of modeled currents. 


\section{ARTICLE IN PRESS}

The comparison with the average model data is presented in Fig. 7, where PHC based KE has been normalized to have same mean as the model based KE. PHC KE is high in the Norwegian sea analogously to the model data (Fig. 7a), but reveals high KE in the middle of the Eurasian Basin and in the Beaufort Sea, where less saline water is located. Model data reveals quite different regions of strong currents, which seem to concentrate along the Siberian shelf, especially off the Laptev Sea (Fig. 7b). The average model data also shows boundary currents flowing around the whole Arctic Basin. The two regions of the high PHC KE in the Arctic Ocean are separated from each other by the Lomonosov Ridge. If these two regions of high PHC KE are relatively separate structures with less significant water transport between the two Arctic sub-basins than the modeled circulation, they might maintain the $\mathrm{APE}_{0}$ gradient in the Arctic Ocean, which was shown in Fig. 6a and introduced in the previous section.

As discussed above, the two regions of high PHC KE actually represent the where the vertical shear of the baroclinic flow is high. If the baroclinic flow component is significant at these regions, the magnitude and orientation of the real current remains unknown. In addition, the PHC data set has been constructed from relatively sparse observations scattered in time and space by applying statistical methods. Therefore the density gradients computed from the PHC data could be biased due to the lacking observations. These caveats do not change the fact that the $\mathrm{APE}_{0}$ gradient vanishes in the AOMIP model simulations as a result of the modeled basin circulation.

(a)

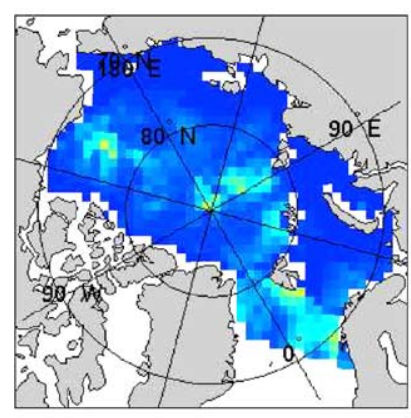

(c)

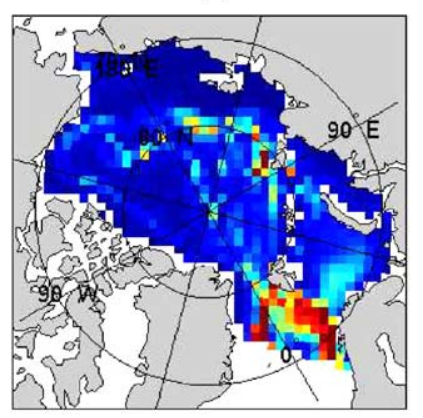

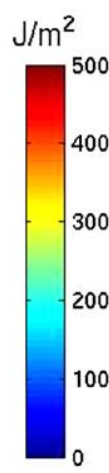

$\mathrm{J} / \mathrm{m}^{2}$

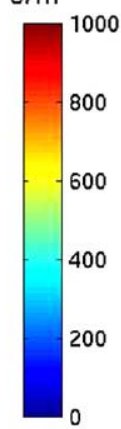

(b)

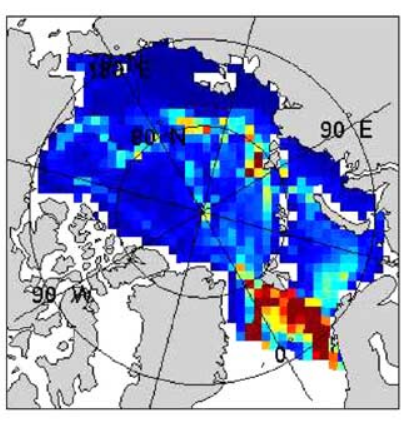

(d)

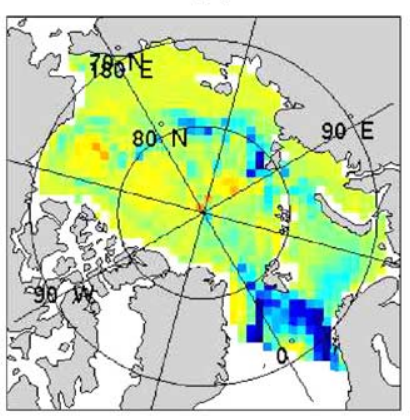

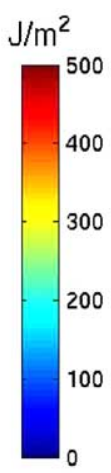

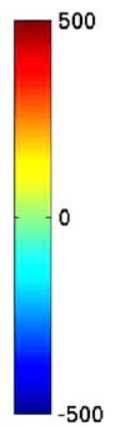

Fig. 7. Annual-average fields of kinetic energy KE for (a) PHC climatology, (b) the mean field of the model data, (c) the standard deviation field of the model data, and (d) bias (PHC-model mean) field in 1978. The vertical integral extends from the sea floor to the surface. 


\section{ARTICLE IN PRESS}

The models deviate where the modeled currents are strong (Fig. 7c), because of the different flow patterns of the individual models. The difference between the PHC and the mean model data (Fig. 7d) shows the regions of KE that do not match. These regions are located along the Siberian shelf break and in the middle of the Canadian and Eurasian Basins.

In order to better understand how the circulation of the models vary with depth, four layers were defined: surface layer $(0-50 \mathrm{~m})$, subsurface layer $(50-200 \mathrm{~m})$, Atlantic layer $(300-800 \mathrm{~m})$ and deep water layer (deeper than $500 \mathrm{~m}$ ).

\subsubsection{Surface layer $(0-50 \mathrm{~m})$}

The surface layer kinetic energy is presented in Fig. 8 and in Table 4. Most models and PHC show high KE values in the GIN Seas and close to the Fram Strait, where waters are only partially ice-covered. NYU model has thick ice cover over the GIN Seas insulating ocean from the atmosphere and reducing the momentum flux (see Table 4 and Fig. 8e). The daily mean of IOS model result in high KE (see Table 4 and Fig. 8d). GSFC has the highest monthly KE in the surface layer. UW model has high KE along the Siberian shelf north of Svalbard (Fig. 8g). The modeled mean KE is about 4-5 times of the one derived from the stratification (Table 4).

Following the AOMIP protocol the models applied daily wind forcing. The mean daily kinetic energy due to the wind can be estimated from the annual mean flux $1.2 \mathrm{~mW} \mathrm{~m}^{-2}$ (see end of Section 2.3.1) to be $100 \mathrm{~J} \mathrm{~m}^{-2}$, which is comparable to the modeled surface layer energy content in the marginal ice zone and the areas of open water (Fig. 8). In the central Arctic, which is mainly covered by ice, only a small fraction of the wind energy penetrates the ocean generating surface currents.

\subsubsection{Subsurface layer $(50-200 \mathrm{~m})$}

The subsurface layer kinetic energy is presented in Fig. 9 and in Table 4. The KE values are generally lower than the values in the surface layer. Especially the KE of daily IOS model data, generated mainly by the wind, attenuates rapidly with depth in the surface layers. GSFC model has the weakest attenuation, which may be due the applied $\sigma$-coordinate system increasing the layer thickness and thus reducing the vertical resolution over the deep ocean.

PHC climatology shows relatively high $\mathrm{KE}$ in the central Canadian Basin (Fig. 9a). AWI, GSFC, IOS, NYU and RAS models have high KE in the Barents sea toward the Kara Sea (Fig. 9b-f). This follows from the transport of Atlantic water to the Arctic Ocean through the Barents Sea and indicates that this transport process modifies significantly the whole Arctic Ocean circulation and stratification. UW has strong currents along the Siberian shelf connected to anticyclonic circulation around the Arctic Ocean (Fig. 9g).

\subsubsection{Atlantic layer $(300-800 \mathrm{~m})$}

The kinetic energy seems to be spatially concentrated along the pathways of inflowing Atlantic water (see Fig. 12). The Atlantic layer kinetic energy is presented in Fig. 10 and in Table 4. In this layer the mean KE has generally decreased from the mean values in the subsurface layer. Characteristics of the modeled water circulation in this layer varies considerably across the models.

AWI and IOS models reveal a cyclonic pattern around the Arctic Basin (Figs. 12a and c), while the other models show less complete boundary currents. IOS model has strong flow component caused by the Neptune parameterization (Nazarenko et al., 1998; Holloway, 1987) producing 


\section{ARTICLE IN PRESS}

(a)

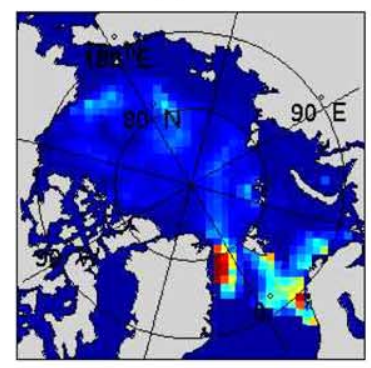

(c)

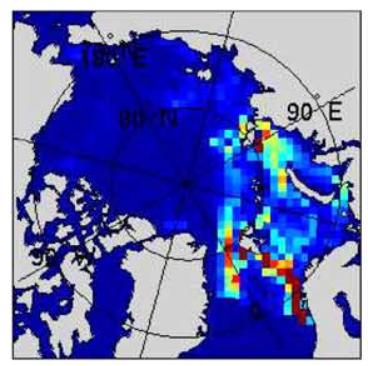

(e)

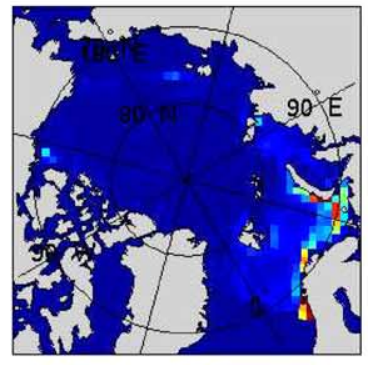

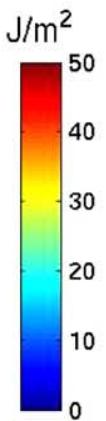

$\mathrm{J} / \mathrm{m}^{2}$

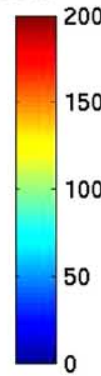

$\mathrm{J} / \mathrm{m}^{2}$

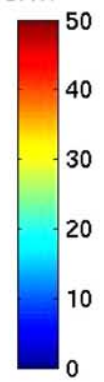

(g)

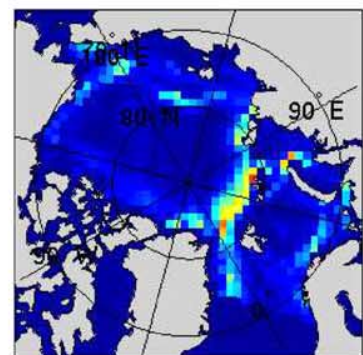

(b)

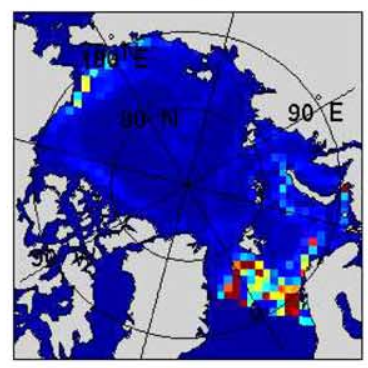

(d)
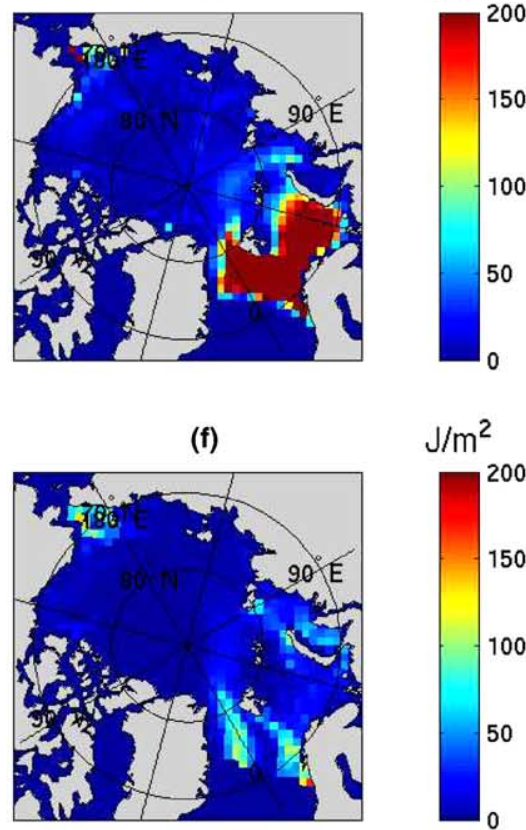

$\mathrm{J} / \mathrm{m}^{2}$

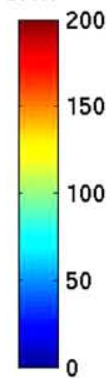

$\mathrm{J} / \mathrm{m}^{2}$

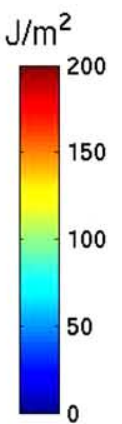

200

150

100

0

00

\section{0}

00

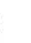

.




\section{ARTICLE IN PRESS}

Table 4

Annual mean values of the monthly kinetic energy in four layers

\begin{tabular}{|c|c|c|c|c|}
\hline & $0-50 \mathrm{~m}\left(\mathrm{~J} \mathrm{~m}^{-3}\right)$ & $50-200 \mathrm{~m}\left(\mathrm{~J} \mathrm{~m}^{-3}\right)$ & $300-800 \mathrm{~m}\left(\mathrm{~J} \mathrm{~m}^{-3}\right)$ & $>500 \mathrm{~m}\left(\mathrm{~J} \mathrm{~m}^{-3}\right)$ \\
\hline PHC, arctic & 0.11 & 0.05 & 0.01 & 0.004 \\
\hline AWI & 0.48 & 0.29 & 0.14 & 0.04 \\
\hline GSFC & 0.62 & 0.47 & 0.19 & 0.15 \\
\hline IOS & 1.71 & 0.21 & 0.08 & 0.06 \\
\hline NYU & 0.06 & 0.04 & 0.013 & 0.011 \\
\hline RAS & 0.36 & 0.18 & 0.05 & 0.03 \\
\hline UW & 0.47 & 0.25 & 0.06 & 0.05 \\
\hline
\end{tabular}

barotropic, basin-scale, topography-guided flow. The Canadian Basin deep water is less saline (34.7 psu) than in the Eurasian Basin (34.8 psu), but the difference is smaller than the one of AWI model. The generation mechanism of the cyclonic boundary current of AWI model is under investigation. These two models have clearly higher mean KE in the Atlantic layer than rest of the models (Table 4).

The deep water flow of GSFC model stops in the Beaufort Gyre (Fig. 12b) corresponding to its stratification. The anomalous ice conditions of NYU model developed during 30-year experiment has caused a stratification pattern with relatively warm and fresh (34.2 psu) water in the Eurasian Basin and cold, saline (34.5 psu) water in the Canadian Basin, resulting in flow from the Canadian Basin through the Fram Strait to the northern North Atlantic (Fig. 12d). NYU model has now comparable, but still smaller, KE values than the other models indicating the ice cover does not significantly affect the current speed at these depths (Table 4).

RAS model does not have evident horizontal deep water circulation pattern. Salinity gradients in the Canadian Basin are weak and strongest flows are located along the Siberian shelf break, close to the Fram Strait and in the Chukchi Sea (Fig. 12e). UW model has anticyclonic circulation pattern (Fig. 12f), which is even more evident in the upper layers (not shown). This anticyclonic circulation dominates the entire water column of UW model from the upper layers down to the Atlantic layer.

A view of the deep water circulation in the Arctic ocean is sketched in Fig. 13. This view is in accordance with the earlier views of Rudels et al. (1994) and McLaughlin et al. (1996). In Fig. 13 cyclonic boundary currents flow around the Arctic Basin and its sub-basins.

\subsubsection{Deep water layer (deeper than $800 \mathrm{~m}$ )}

The kinetic energy of the deep water layer is presented in Fig. 11 and in Table 4. KE of the PHC geostrophic currents is on the average much smaller than the KE of the modeled currents. The deep water KE of PHC is high, however, close to St. Anna Through, central Eurasian Basin and in the Canadian Basin (Fig. 11a).

AWI model has high KE values in the Arctic Ocean close to the same location than PHC, but also high KE values connecting the two main basins of the Arctic Ocean. The cyclonic circulation is apparent (Fig. 11b), while the mean layer KE has dropped significantly by one magnitude (Table 4). The cyclonic circulation pattern is even more evident for IOS model (Fig. 11d) and due the barotropic-type Neptune parameterization the average KE in the deep water layer is only slightly smaller than in the Atlantic layer (Table 4). 


\section{ARTICLE IN PRESS}

P. Uotila et al. / Ocean Modelling xxx (2005) xxx-xxx

(a)

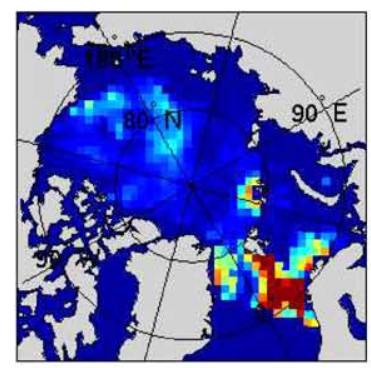

(c)

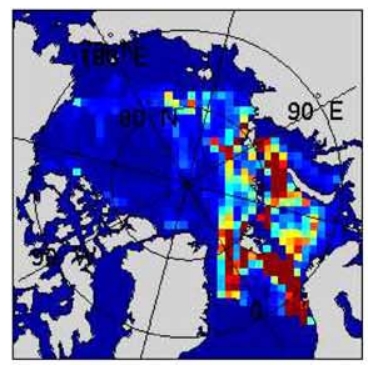

(e)

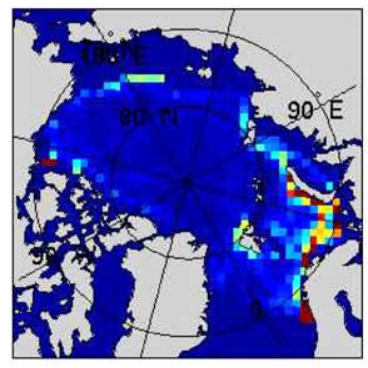

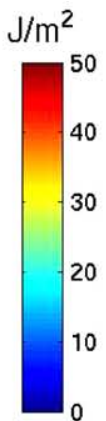

$\mathrm{J} / \mathrm{m}^{2}$

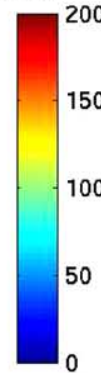

$\mathrm{J} / \mathrm{m}^{2}$

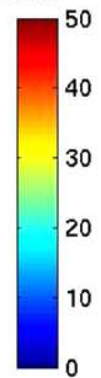

(b)

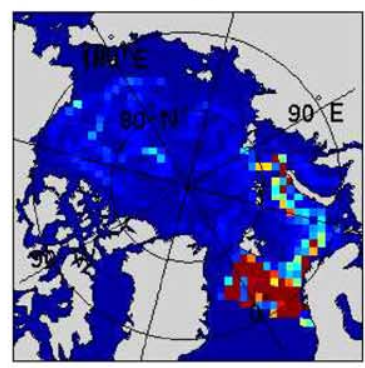

(d)

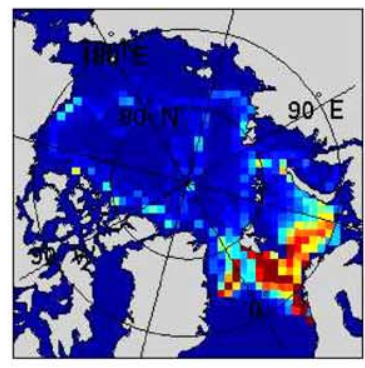

(f)

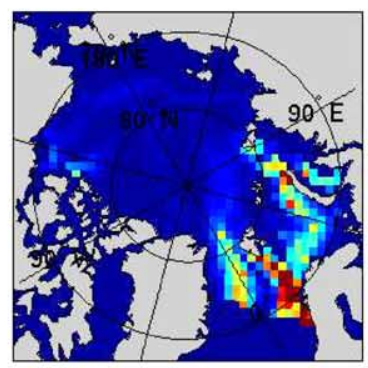

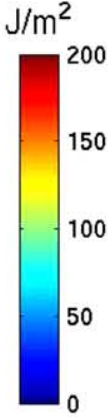

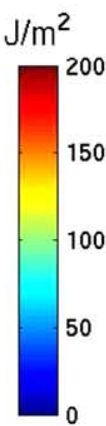

$\mathrm{J} / \mathrm{m}^{2}$

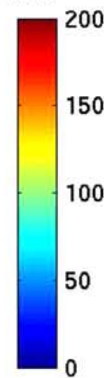

150

100

50

$\omega_{0}$

(g)

$\mathrm{J} / \mathrm{m}^{2}$
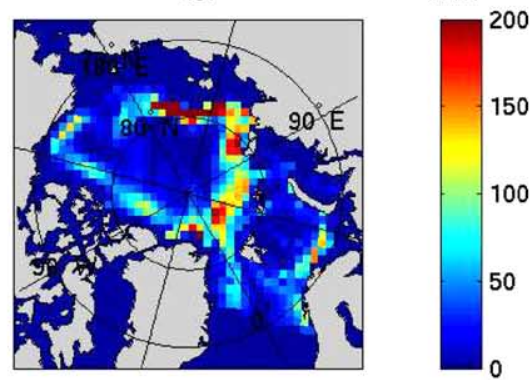

Fig. 9. Annual-average field of kinetic energy KE for the subsurface layer (50-200 m). (a) PHC climatology, (b) AWI, (c) GSFC, (d) IOS, (e) NYU, (f) RAS and (g) UW models in 1978. 


\section{ARTICLE IN PRESS}

(a)

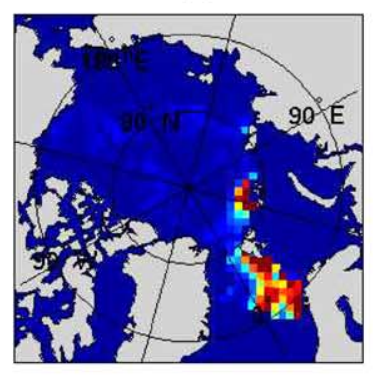

(c)

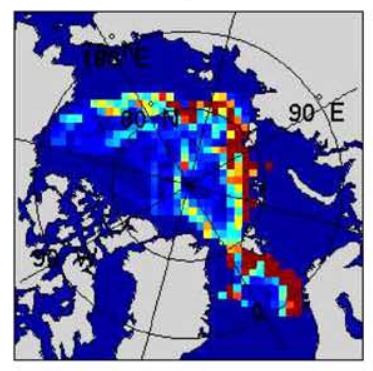

(e)

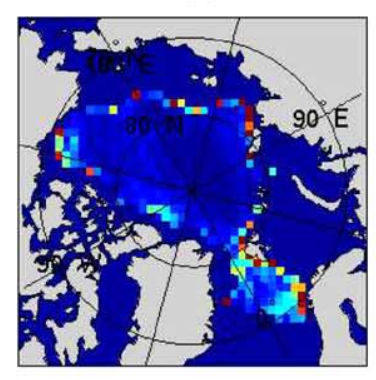

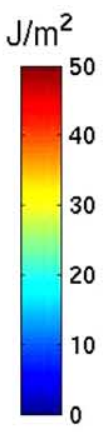

$\mathrm{J} / \mathrm{m}^{2}$

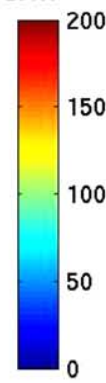

$\mathrm{J} / \mathrm{m}^{2}$

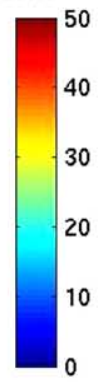

(b)

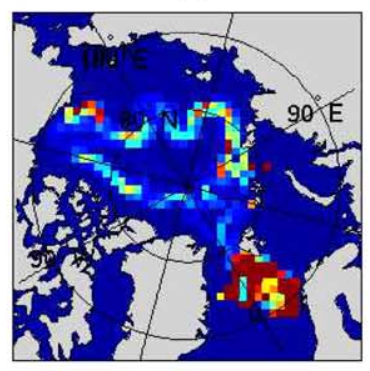

(d)

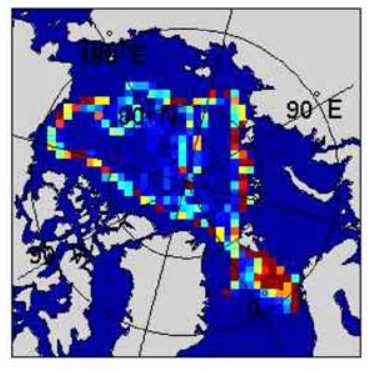

(f)

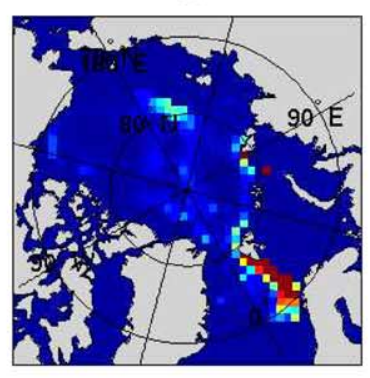

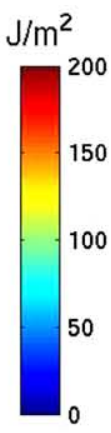

$\mathrm{J} / \mathrm{m}^{2}$

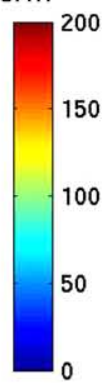

$\mathrm{J} / \mathrm{m}^{2}$

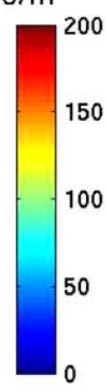

(g)

$\mathrm{J} / \mathrm{m}^{2}$
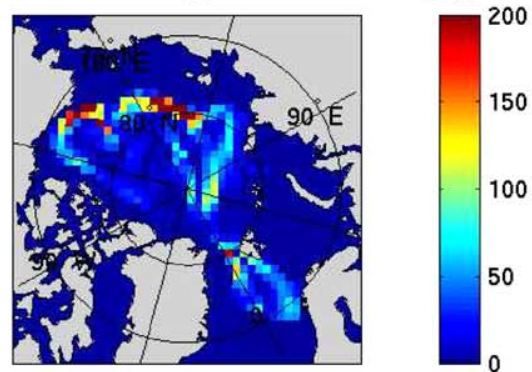

Fig. 10. Annual-average field of kinetic energy KE for the Atlantic water layer (300-800 m). (a) PHC climatology, (b) AWI, (c) GSFC, (d) IOS, (e) NYU, (f) RAS and (g) UW models in 1978. 


\section{ARTICLE IN PRESS}

(a)

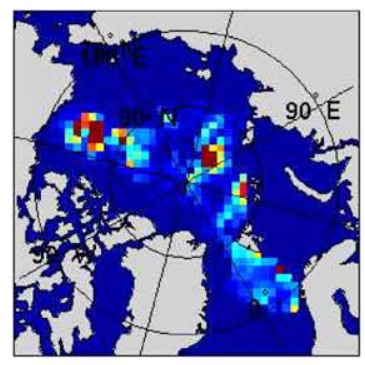

(c)

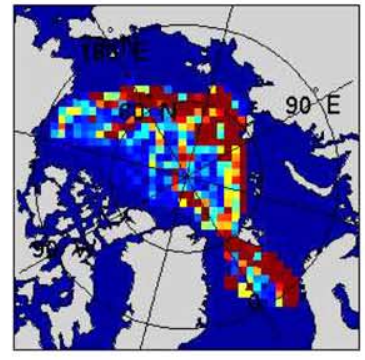

(e)

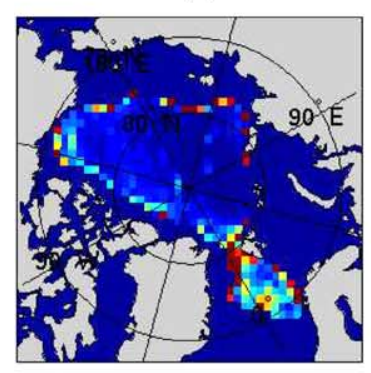

(b)

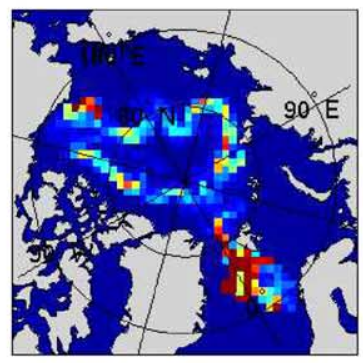

(d)

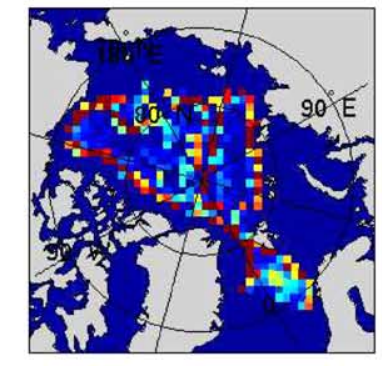

$\mathrm{J} / \mathrm{m}^{2}$

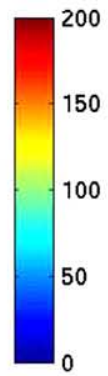

$\mathrm{J} / \mathrm{m}^{2}$
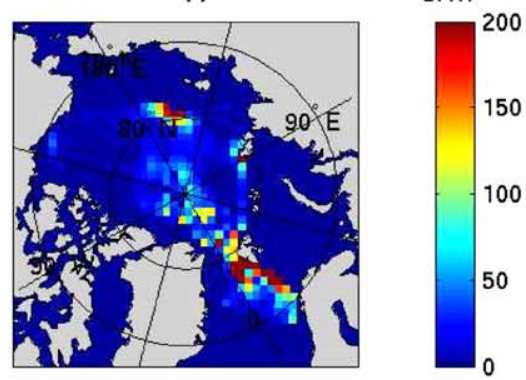

$\mathrm{J} / \mathrm{m}^{2}$

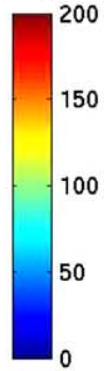

$\mathrm{J} / \mathrm{m}^{2}$

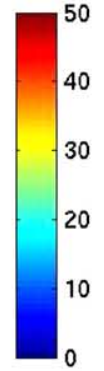

$\mathrm{J} / \mathrm{m}^{2}$

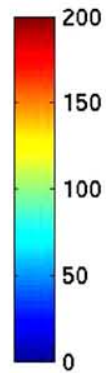

(g)
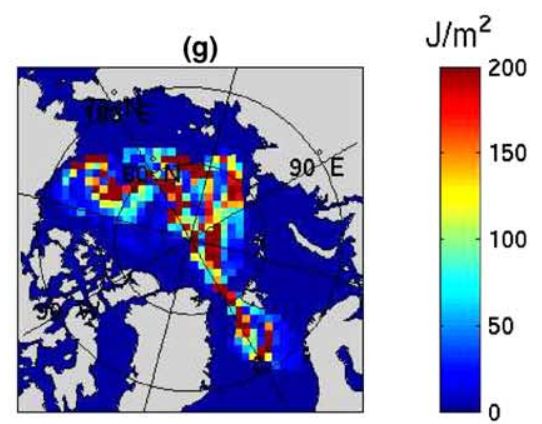

Fig. 11. Annual-average field of kinetic energy KE for the deep water layer (depth greater than $500 \mathrm{~m}$ ). (a) PHC climatology, (b) AWI, (c) GSFC, (d) IOS, (e) NYU, (f) RAS and (g) UW models in 1978. 


\section{ARTICLE IN PRESS}
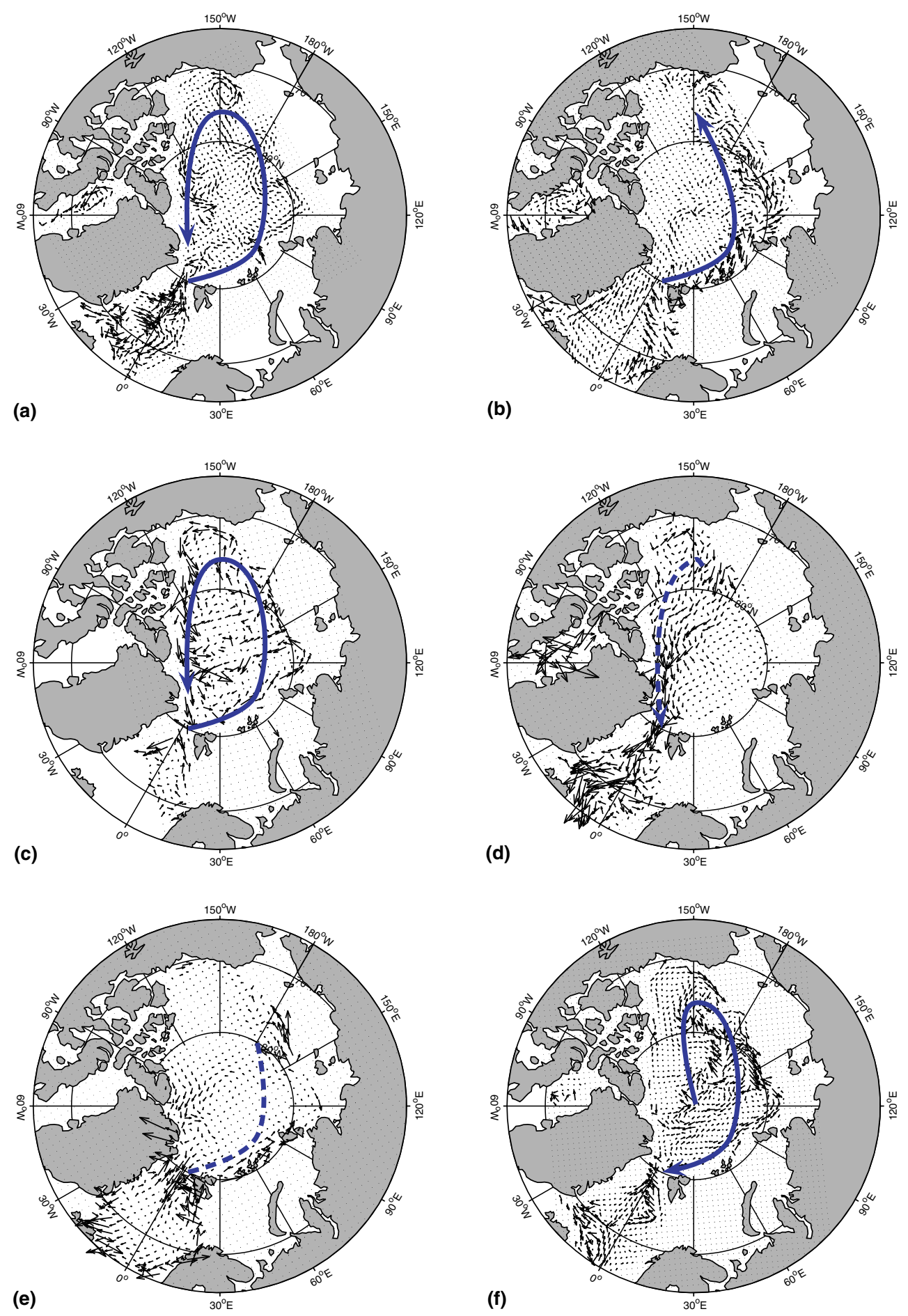

Fig. 12. Modeled water circulation, integrated from the depth of $-500 \mathrm{~m}$ to the bottom. (a) AWI, (b) GSFC, (c) IOS, (d) NYU, (e) RAS and (f) UW. 


\section{ARTICLE IN PRESS}

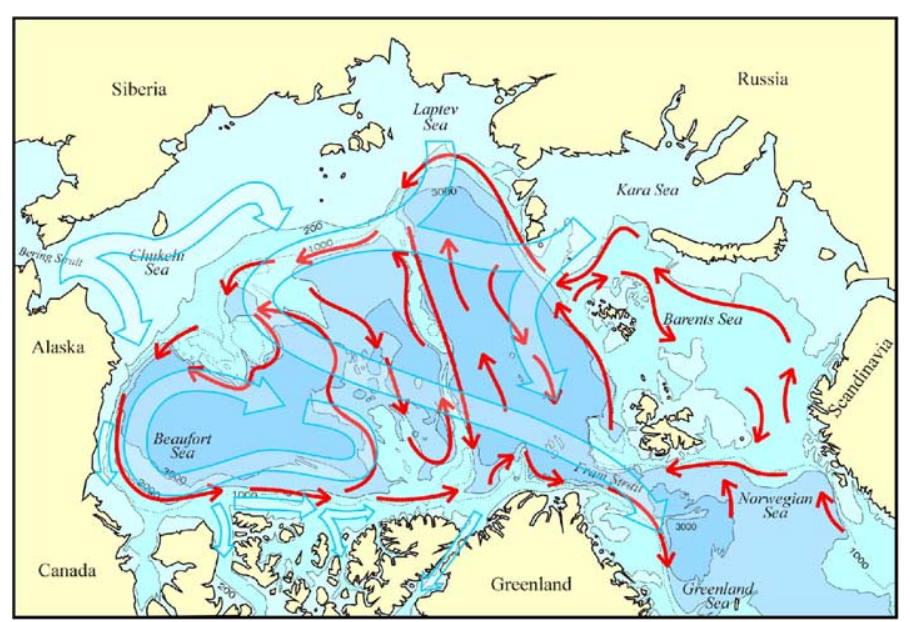

Fig. 13. A view of the Arctic undercurrents (red, solid arrows). (For interpretation of the references in colour in this figure legend, the reader is referred to the web version of this article.)

GSFC model has still a lot of KE in the deep water layer, where the mean energy is almost the same as in the Atlantic layer (Fig. 11 and Table 4). This could be due to the applied $\sigma$-coordinate system decreasing the vertical resolution of the model with the ocean depth. It seems that the relatively high surface layer KE of GSFC affects the flow in the abyss. The high KE of GSFC regions are now broader than in the Atlantic layer, covering more the interior of the Arctic Ocean. This indicates strong flows close to the sea floor. The mean KE of NYU model deep water has not decreased much from the value in the Atlantic layer (Table 4). The circulation of NYU in the deep water layer has resembling pattern than the one in the Atlantic layer, being only much weaker (Fig. 11e).

The mean KE of RAS model in the deep water is almost the same than in the Atlantic layer (Table 4). High KE values occur close to the Fram Strait and at the Siberian shelf in front of the East-Siberian Sea (Fig. 11f). In the latter location the KE has increased towards the bottom being weaker in the Atlantic layer (Fig. 10f). In the deep water layer the mean KE of UW model is close to the corresponding mean value in the Atlantic layer (Table 4). There are areas of high KE through the Eurasian Basin and in the Canadian Basin resembling the KE distribution of GSFC model and the weaker KE of PHC derived geostrophic currents.

\subsubsection{Energy fluxes}

In order to obtain the budget of the kinetic energy (8b), the pressure gradients were first resolved from the momentum equation as a residual term by utilizing the horizontal flow velocity and the density data. After computing pressure gradients, the terms $A, P, F$ and $D$ were calculated. The GSFC model computes the vertical viscosity by using Mellor-Yamada turbulent closure scheme. We assumed a constant $K_{\mathrm{v}}=10^{-3} \mathrm{~m}^{2} \mathrm{~s}^{-1}$ for this model in the Arctic Ocean, where convective processes do not extend deep and so a constant value is justified. We also computed friction terms using $K_{\mathrm{v}}=10^{-4} \mathrm{~m}^{2} \mathrm{~s}^{-1}$, decreasing results less than $5 \%$ compared to the former value of $K_{\mathrm{v}}$. 


\section{ARTICLE IN PRESS}

The distributions of the energy fluxes have rather similar shapes, having most of the values close to zero and p.d.f. curve decreasing steeply towards larger values. The $75 \%$ percentile value of the distributions are presented in Table 5. The regions of high energetic boundary currents seem to approximately have energy fluxes higher than the $75 \%$ percentile. Thus the values presented in Table 5 present lower level estimates of the energy fluxes in the deep boundary currents.

The advection term is about one magnitude smaller than the others and the model energy balance at depth is mostly between the remaining three terms. The $75 \%$ percentile of the advection term $A$ seem to be somewhat high for GSFC model, but still significantly smaller than the other terms (Table 5). The $P$ term appears to be high close to the bottom. Values elevated from the sea floor occur especially with AWI and to some extent with NYU and IOS. In hydrostatic models $P$ is the only term describing conversion from PE to KE. When the flow is in geostrophic balance $P$ is zero. When $P$ is positive, the flow is from higher to lower pressure and PE is converted to KE. This seem to be the prevalent direction for the models. The spatial distribution of the dissipation $D$ resembles the one of $P$. In addition, the active regions of high diffusion follow $P$ and $D$ distributions.

AWI model has negative $P$ values close to the Fram Strait and St. Anna Through. There KE is transformed to PE and currents maintain density gradients. In addition, GSFC reveals negative $P$ values in St. Anna Trough. According to Ivchenko et al. (1997) this type of conversion is enabled in the eddy-resolving models. In their study Ivchenko et al. (1997) conclude large conversion from kinetic to potential energy in the Southern Ocean. This is probably not the case for the deep water flow of AWI model, but is merely related to dynamically active in- and outflows through the narrow straits. In addition, IOS model, which employs the Neptune parameterization describing eddies, has apparent negative $P$ values in deep Arctic Ocean, beside the shelf slope.

Vertical profiles of the annual mean energy flux terms are presented in Fig. 14. $A$ is again small compared to the other terms. $D, F$ and $P$ terms generally increase towards the surface, although IOS and UW models seem to have maxima of $F$ and $P$ at $2000 \mathrm{~m}$ depth.

The relative importance of the energy flux terms and their mean balance is somewhat different in the models (Table 5). $P / F$ ratio of $75 \%$ percentile boundary values varies from 0.5 (NYU) to 1.5 (GSFC). The corresponding $P / D$ ratio has values from 0.5 (NYU) to 3.2 (IOS), and $D / F$ from 0.4 (IOS) to 1.8 (GSFC). GSFC model is the most energetic, but it has the second highest dissipation and relatively small diffusion when compared to the pressure term. Thus the mechanical energy in

Table 5

Energy-diagnostics, $75 \%$ percentile values of kinetic energy (KE), potential energy $(P)$, dissipative term $(D)$, diffusion term $(F)$ and advection of the mechanical energy $(A)$ distributions

\begin{tabular}{llcccl}
\hline & KE & $P$ & $D$ & $F$ & $A$ \\
\hline AWI & 0.16 & 6.1 & 2.9 & 5.0 & 0.15 \\
GSFC & 0.41 & 4.2 & 5.1 & 2.8 & 0.70 \\
IOS & 0.13 & 64 & 20 & 58 & 0.13 \\
NYU & 0.04 & 0.05 & 0.1 & 0.09 & 0.02 \\
RAS & 0.20 & 7.3 & 4.5 & 7.2 & 0.16 \\
UW & 0.14 & 7.4 & 3.9 & 7.3 & 0.12 \\
\hline
\end{tabular}

The $75 \%$ percentile is the limit where $75 \%$ of the distribution are less than the limit and $25 \%$ exceed the limit. Fluxes are in $10^{-7} \mathrm{~W} \mathrm{~m}^{-3}$ and $\mathrm{KE}$ in $\mathrm{J} \mathrm{m}^{-3}$. 


\section{ARTICLE IN PRESS}

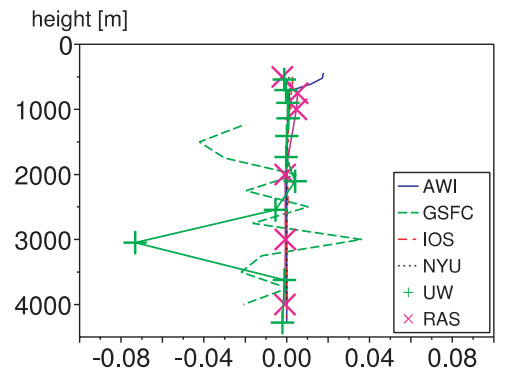

(a)

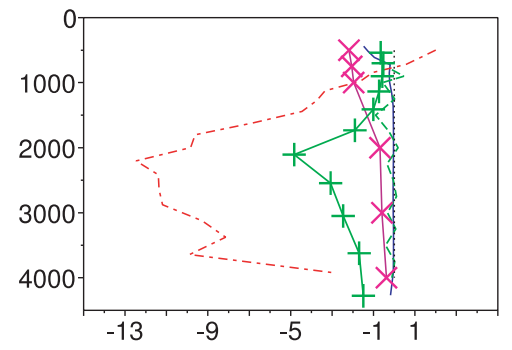

(c)

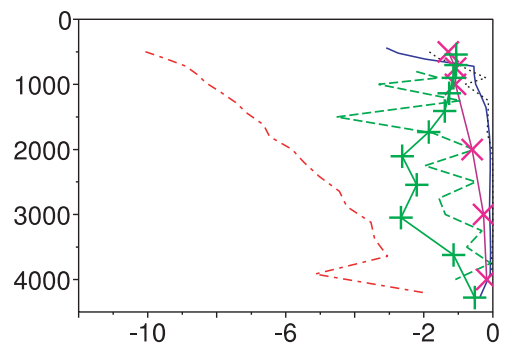

(b)

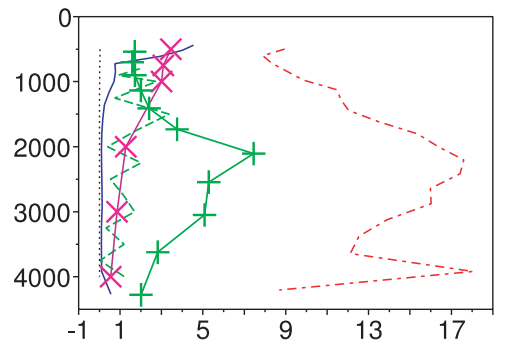

(d)

Fig. 14. Vertical profiles of the annual and horizontal mean energy fluxes in 1978. Fluxes are in $10^{-7} \mathrm{~W} \mathrm{~m}{ }^{-3}$. (a) Advection, (b) dissipation, (c) diffusion and (d) pressure.

Arctic Ocean is not diffused, but dissipated and the boundary current is not formed. IOS and AWI models, on the other hand, have strong $P$ and $F$ compared to $D$, and the mechanical energy is spread in Arctic Ocean-through eddy-diffusive processes. NYU model has the smallest $P / D$ ratio indicating weak currents and significance of the diffusive processes, balanced by dissipation. Although RAS and UW models have almost as high $P / D$ ratios as AWI, the dissipation is higher and diffusion smaller. Even though we derive same rough statistics from model data, the energetically active regions are distributed quite differently in Arctic Ocean. Therefore it is probable the processes affecting the energy balance can be initiated due to very different reasons. In addition, the discussion above is valid for the average balance over the most energetic grid cells, which dominate the modeled circulation pattern.

\section{Conclusions}

We have analyzed the energetics of the six Arctic Ocean models. In addition to the basic components of the energy, internal, potential and kinetic, we studied the terms in the energy equation (8a) beside the initial quantities of temperature, salinity and velocity, and the terms in the momentum equation. Thus we achieve an integrated view of the model data.

Even though the models had the same initial conditions, forcing and some parameters following the AOMIP protocol, their energetics is remarkably different after a 30-year run. Many parameterizations, however, differ between the models. There are some systematic differences in the energy components derived from the model data versus the ones derived from the climatology. None 


\section{ARTICLE IN PRESS}

of the models produce available potential energy distribution similar to the one derived from PHC climatology due to too saline Canadian Basin. Steele et al. (2001a) obtained similar results from model runs which used different wind forcing data sets, while in our study the same wind forcing data is applied. Accordingly, our result emphasize the modeled salinity bias is due to the simulation of the freshwater source, which could be common to all the models or due to the common wind forcing data set, producing similarly biased salinities in the Beaufort Gyre.

The PHC climatology has a larger annual variation of internal and potential energies than the ones calculated from the model data. PHC available potential energy is relatively high in the Eurasian Basin compared to the one in the Canadian Basin. The models, in general, seem to produce large differences between the available potential energy in the GIN Seas and in the Eurasian Basin, but not between the Eurasian and the Canadian sub-basins of the Arctic Ocean. This indicates that modeled circulation patterns have modified the initial stratification remarkably.

The balance of the kinetic energy in the deep ocean was assumed to be between the local time derivative, advection, pressure term, diffusive term and dissipation. Models reveal, on the average, positive pressure term, indicating flows from high-to-low pressure and $\mathrm{PE} \rightarrow \mathrm{KE}$ conversion. The mean balance of the kinetic energy at deep ocean is between the pressure term, diffusion of the kinetic energy and dissipation. The advection term is significant locally. The energy balances of the models differ significantly in the abyss, notably regarding the conversion of potential and kinetic energies.

The kinetic energy computed from the model data differs significantly from the kinetic energy of the geostrophic currents derived from the PHC climatology. At the subsurface layer an important process produced by the models is the wind-driven transport of the Atlantic water across the relatively shallow Barents Sea to the Arctic Ocean. At greater depths, the modeled kinetic energies are higher and located along the arctic shelves producing boundary currents circulating around the basin. This model-produced circulation is controlled by the components in the momentum equation, which do not participate in the geostrophic balance, like advection and friction and is in accordance with the understanding of the possible generation mechanisms of the arctic boundary currents. Accordingly the models' stratification has been modified significantly from the initial having strong geostrophic currents where boundary currents occur. On the contrary to the models, the PHC derived geostrophic currents show two separate deep water circulation cells separated by the Lomonosov Ridge. These two geostrophic circulation cells sustain the two water masses of Canadian and Eurasian Basins, which is evident as an $\mathrm{APE}_{0}$ gradient.

The narrow boundary undercurrents along steep topography are the strongest circulation features in the deep, slowly moving Arctic Ocean and these currents often may have maximum at intermediate depths or near the bottom (Muench et al., 2000; Aagaard and Carmack, 1994). They are expected to be generally cyclonic and opposite to the flow of ice and the surface mixed layer. The generation mechanism for these currents is argued to be through interaction of eddies with topographic features (Nazarenko et al., 1998; Polyakov, 2001). Small, intensive eddies in the Canadian Basin at 400-500 m have been reported (Muench et al., 2000; Aagaard and Carmack, 1994). The AOMIP models result in significantly different representation of the boundary currents. Two models have evident cyclonic circulation, which is strongest at the depth between 300 and $800 \mathrm{~m}$.

The KE of the geostrophic currents computed from the climatological data does not show boundary undercurrents and the wind-driven currents in the Barents Sea to the same extent than 
the ones derived from the model data. In case of the barotropic boundary current, having no associated density gradient, one can not derive information about the current from the density gradients only. It is likely, however, that regions of high density gradients identify regions of strong currents with strong vertical shears. The hydrographic data set estimated from sparse observations by using statistical methods may be biased by lacking ocean physics. Horizontal density gradients derived from modeled stratification reveal patterns similar to, although weaker than the boundary currents. This suggests that physically more realistic hydrographic arctic data sets should be created with the aid of ocean models by applying data assimilation methods. These kind of activities will be carried out within the SEARCH-project utilizing models to synthesize observations in the Arctic.

Energy diagnostics is an important part of analyzing the of the model-produced data, which can reveal deficiencies in the physics of the models. We recommend more detailed energetics to be carried out in the future. The energetics of ocean circulation models is difficult to construct by post-processing the basic quantities like temperature, salinity, and velocity and models would benefit by having built-in energy analysis routinely operated, stored and utilized.

AOMIP performance in the Arctic has been studied. Comparisons have revealed deficiencies in the suite of models and showed how to enhance the models. In order to gain better performance in the Arctic, AOMIP models have to be calibrated and validated even more carefully against observations. This goal will be achieved by utilizing standard, observation based data sets, which will be established by AOMIP. The ultimate goal of AOMIP is to introduce the physics of the Arctic Ocean as accurate as possible in the models. In the future AOMIP will be even more constrained in terms of the types of experiments it performs. Therefore AOMIP will be able to be more explicit in identifying as to why model results are different from another.

\section{Acknowledgments}

Authors of this study were supported by the International Arctic Research Center (IARC). Petteri Uotila thanks the Arctic Region Supercomputing Center and the Academy of Finland for their support of his research activities at NYU. David M. Holland is grateful to the NSF for support through grant OPP-0084286. Nikolai Yakovlev was supported by Russian Foundation for Basic Research through grant 03-05-64357.

\section{References}

Aagaard, K., Carmack, E.C., 1994. The Arctic Ocean and climate: a perspective, in the Polar Oceans and their role in shaping the global environment. Geophysical Monograph 85, 5-20.

Apel, J.R., 1987. Principles of Ocean Physics. Academic Press, London, p. 634.

Gerdes, R., Schauer, U., 1997. Large-scale circulation and water mass distribution in the Arctic Ocean from model results and observations. Journal of Geophysical Research 102, 8467-8483.

Gerdes, R., Hurka, J., Karcher, M., Kauker, R., Koeberle, C., in press. Simulated history of convection in the Greenland and Labrador seas 1948-2001, AGU monograph Climate Variability of the Nordic Seas, Bjerknes Centre for Climate Research, Bergen, Norway. 


\section{ARTICLE IN PRESS}

Griffies, S., Hallberg, B., 2000. Biharmonic friction with a smagorinsky-like viscosity for use in large-scale Eddypermitting ocean models. Monthly Weather Review 128, 2935-2946.

Häkkinen, S., 1999. A simulation of thermohaline effects of a great salinity anomaly. Journal of Climate 12, 1781-1795.

Holland, D.M., 2001. An impact of sub-grid-scale ice-ocean dynamics on sea ice cover. Journal of Climate 14, 15851601.

Holland, D.M., Mysak, L.A., Oberhuber, J.M., 1996. Simulation of the mixed-layer circulation in the Arctic Ocean. Journal of Geophysical Research 101, 1111-1128.

Holloway, G., 1987. Systematic forcing of large-scale geophysical flows by Eddy-topography interaction. Journal of Fluid Mechanics 184, 463-476.

Holloway, G., Sou, T., 2002. Has Arctic sea ice rapidly thinned?. Journal of Climate 15, 1691-1701.

Huang, R.X., 1998. Mixing and available potential energy in a Boussinesq Ocean. Journal of Physical Oceanography 28, 669-678.

Huang, R.X., 1999. Mixing and Energetics of Oceanic Circulation. Journal of Physical Oceanography 29, 727-746.

Ivchenko, V.O., Trequirer, A.M., Best, S.E., 1997. A kinetic energy budget and internal instabilities in the fine resolution Antarctic model. Journal of Physical Oceanography 27, 5-22.

Karcher, M.J., Gerdes, R., Kauker, F., Köberle, C., 2003. Arctic warming: evolution and spreading of the 1990s warm event in the Nordic seas and the Arctic Ocean. Journal Geophysical Research 108 (C2), 10.1029/2001JC001265.

Levitus, S., 1982. Climatological atlas of the world ocean. NOAA Prof. Pap. 13, 17 microfiches, US Government Printing Office, Washington, DC, p. 163.

Lorenz, E.N., 1955. Available potential energy and the maintenance of the general circulation. Tellus 7, 157-167.

McLaughlin, F.A., Carmack, E.C., Macdonald, R.W., Bishop, J.K.B., 1996. Physical and geochemical properties across the Atlantic/Pacific water mass front in the southern Canadian Basin. Journal of Geophysical Research 101, $1183-1197$.

Muench, R.D., Gunn, J.T., Whitledge, T.E., Schlosser, P., Smethie, W., 2000. An Arctic Ocean cold core eddy. Journal of Geophysical Research-Oceans 105 (CI0), 23997-24006.

Nazarenko, L., Holloway, G., Tausnev, N., 1998. Dynamics of transport of "Atlantic signature" in the Arctic Ocean. Journal of Geophysical Research 103, 31003-31015.

Oort, A.H., Anderson, L.A., Peixoto, J.P., 1994. Estimates of the energy cycle of the oceans. Journal of Geophysical Research 99 (C4), 7665-7688.

Oort, A.H., Ascher, S.C., Levitus, S., Peixoto, J.P., 1989. New estimates of the available potential energy in the World ocean. Journal Geophysical Research 94 (C3), 3187-3200.

Polyakov, I., 2001. An eddy parameterization based on maximum entropy with application to modeling of the Arctic Ocean circulation. Journal of Physical Oceanography 31, 2255-2270.

Proshutinsky, A., Steele, M., Zhang, J., Holloway, G., Steiner, N., Häkkinen, S., Holland, D., Gerdes, R., Kpeberle, C., Kärcher, M., Johnson, M., Maslowski, W., Walczowski, W., Hibler, W., Wang, J., 2001. Multinational effort studies differences among Arctic Ocean models. EOS 82 (51), 637-644.

Rudels, B., Jones, E.P., Anderson, L.G., Kattner, G., 1994. On the intermediate depth waters of the Arctic Ocean. In: Johannessen, O.M., Muench, R.D., Overland, J.E. (Eds.), The Polar Oceans and their role in shaping the global environment. Geophysical Monograph 85, pp. 33-46.

Steele, M., Ernold, W., Häkkinen, S., Holland, D., Holloway, G., Karcher, M., Käuker, F., Maslowski, W., Steiner, N., Zhang, J., 2001a. A drift in the Beaufort Gyre: a model intercomparison. Geophysical Research Letters 28, 2935-2938.

Steele, M., Morley, R., Ermold, W., 2001b. PHC: A global ocean hydrography with a high quality Arctic Ocean. Journal of Climate 14, 2079-2087.

Steiner, N., Holloway, G., Gerdes, R., Hkkinen, S., Holland, D., Karcher, M., Kauker, F., Maslowski, W., Proshutinsky, A., Steele, M., Zhang, J., 2004. Comparing modeled streamfunction, heat and freshwater content in the Arctic Ocean. Ocean Modelling 3-4, 265-284.

Winters, K.B., Lombard, P.N., Riley, J.J., D’Asaro, E.A., 1995. Available potential energy and mixing in densitystratified fluids. Journal of Fluid Mechanics 289, 115-128.

Wunsch, C., Ferrari, R., 2004. Vertical mixing, energy, and the general circulation of the oceans. Annual Review of Fluid Mechanics 36, 281-314. 


\section{ARTICLE IN PRESS}

Yakovlev, N., 2003. Coupled model of ocean general circulation and sea ice evolution in the Arctic Ocean, Izvestiya. Atmospheric and Oceanic Physics 39 (3), 355-368.

Zhang, J., Rothrock, D., Steele, M., 2000. Recent changes in Arctic sea ice: the interplay between ice dynamics and thermodynamics. Journal of Climate 13, 3099-3114. 